\begin{tabular}{|c|l|}
\hline Title & U pstream migration of adult chum and pink sal mon in the Shibetsu River \\
\hline Author(s) & Makiguchi, Y.; Nii, H.; Nakao, K.; Ueda, H. \\
\hline Citation & $\begin{array}{l}\text { Hydrobiologia, 582(1), 43-54 } \\
\text { https://doi.org/40.1007/310750-006-0555-8 }\end{array}$ \\
\hline Issue Date & 2007-05 \\
\hline Doc URL & http://hdl.handle.net/2115/22080 \\
\hline Rights & The original publication is available at www.springerlink.com \\
\hline Type & article (author version) \\
\hline File Information & HB582.pdf \\
\hline
\end{tabular}

Instructions for use 


\title{
Upstream migration of adult chum and pink salmon in the Shibetsu River
}

\author{
Y. Makiguchi ${ }^{1, *}$, H. Nii ${ }^{2}$, K. Nakao ${ }^{2}$, H. Ueda ${ }^{1,3}$ \\ ${ }^{1}$ Division of Environmental Science Development, Graduate School of Environmental Science, \\ Hokkaido University, North 9 West 9, Kita-ku, Sapporo, Hokkaido 060-0809, \\ ${ }^{2}$ Hokkaido Farming Fisheries Promotion Corporation, North 3 West 7, Chuo-ku, Sapporo, \\ Hokkaido 060-0003 \\ ${ }^{3}$ Laboratory of Aquatic Bioresources and Ecosystems, Field Science Center for Northern \\ Biosphere, Hokkaido University, North 9 West 9, Kita-ku, Sapporo, Hokkaido 060-0809, Japan \\ * Corresponding author - Email:yuya-m@fsc.hokudai.ac.jp Tel: +81 11706 2583, \\ Fax: +81-11-706-2598;
}

Keywords: Migratory behavior, Electromyogram (EMG), DT logger, Meandering reconstruction

This paper has not been submitted elsewhere in identical or similar form, nor will it be during the first three months after its submission to Hydrobiologia 


\section{Abstract}

The migratory behavior and swimming patterns of anadromous upstream migratory fish have been poorly described in the Shibetsu River in eastern Hokkaido, Japan. In this 2004 study, we used electromyogram (EMG) transmitters and depth/ temperature (DT) loggers to compare the upstream migratory behavior of adult male chum salmon (Oncorhynchus keta) and pink salmon (O. gorbuscha) in the canalized and reconstructed segments of the Shibetsu River, where a part of canalized section was preliminary reconstructed meander to restore a more natural section. The EMG transmitter and DT logger were externally attached to the left side of the body, below the front edge of the dorsal fin. Fish of both species often migrated along the riverbanks and near the bottom of the water column, sometimes engaged in holding behavior, which was defined as cessation of swimming during their upstream migration for 5 minutes. Modal swimming depth calculated by DT loggers for chum salmon $(0.2-0.4 \mathrm{~m})$ was shallower than pink salmon (0.6-0.8 m). Further, modal swimming speeds measured by calibrated EMG for chum salmon (0.2-0.4 $\left.\mathrm{BL} \mathrm{s}^{-1}\right)$ were slower than pink salmon (1.2-1.4 $\mathrm{BL} \mathrm{s}^{-1}$ ). Pink salmon swam faster as well as in relatively deeper than chum salmon, suggesting that they expend more energy than chum salmon in the reconstructed segment. Based on these results, it seemed likely that the upstream migration behavior of chum and pink salmon was different with species-specific strategies. 


\section{Introduction}

It is well known that Pacific salmon (Oncorhynchus spp.) typically do not feed and must use their stored energy during upstream spawning migration. The upstream migration of anadromous fish can be energetically expensive, particularly when travel distances are long and river environmental conditions are adverse (Bernatchez and Dodson 1987; Leonard and McCormick 1999). Studies using electromyogram (EMG) telemetry found that sex, size and swimming speed patterns of salmon are extremely important factors affecting energy use during upstream migration (Hinch et al. 1996; Hinch and Rand 1998, 2000). Hinch et al. (2002) found that sockeye salmon (O. nerka) were more variable in swimming speeds than pink salmon (O. gorbuscha) though the causes were not entirely clear. These studies on upstream migration behavior of salmon were conducted in long and turbulent rivers like the Fraser River in Canada. Bernatchez and Dodson (1987) compared energetic costs of migration for short- and long-distance upstream migrating anadromous fishes, and concluded that only the long-distance migrants (particularly some stocks of Pacific salmon) swam at optimal speeds. In contrast to the Fraser River, the Shibetsu River in eastern Hokkaido, Japan is short (10.4 km from the estuary to chum salmon's spawning ground). No studies have been done in short and non-turbulent rivers to compare differences in upstream migratory behaviors of pink and chum salmon (O. keta).

In Japan, channel alternation for flood control and irrigation has changed general fish fauna and standing crops (Mizuno and Gose 1981). In the Shibetsu River, the reconstruction of channel alternation to a more natural state was preliminary conducted in March 2002, and additional phases of reconstruction are planning after evaluating the results of preliminary restoration. However, there is only one study on the effect of reconstruction on upstream migratory behavior of chum salmon in the Shibetsu River 
(Akita et al. 2006). More information about upstream migratory behavior of chum salmon and other salmonid species are necessary for further restoration of the Shibetsu River river planned in the future.

EMG telemetry has been used for several years to investigate the factors responsible for variability in migratory energetics of sockeye salmon. EMG transmitters enable us to quantify swimming speeds of individual migrating fish (McKinley and Power 1992; Hinch et al. 1996). Micro-data logger storaging information of ambient depths and temperature also has been used to monitor chum salmon behavior in the sea (Tanaka et al. 1998, $2000,2001)$. However, there has been only one study that used EMG transmitters and depth/temperature (DT) loggers simultaneously to investigate the upstream migration of chum salmon (Akita et al. 2006). Data collected by both EMG transmitter and DT logger enable us to have coupled time-series information for swimming speed and swimming depth. Further, since we need to retrieve the DT logger after releasing a fish, we can find the fish in a river by radio signals from the EMG transmitter.

In this study, we used EMG transmitters and DT loggers to estimate swimming speed and swimming depth of the chum and pink salmon during their upstream migration in both canalized and reconstructed segment in the Shibetsu River. Our main objectives are to compare the two species' upstream migration strategies in the Shibetsu River in detail using the EMG transmitter and the DT logger. 


\section{Materials and methods}

Study area

The Shibetsu River, located in eastern Hokkaido, Japan, flows to the Nemuro Straight with a total length of about $78 \mathrm{~km}$ and a drainage basin that occupies $671 \mathrm{~km}^{2}$. Over the past century, the river has been altered from a meandering, complex river system, to a canalized flood-control canal. Recently a segment of the Shibetsu River located $8.4 \mathrm{~km}$ upstream from the river mouth was reconstructed to restore the canalized river to a more natural state. Early in 2004, artificial large woody debris (LWD) was installed in the middle of reconstructed segment. It is well known that natural LWD has many impacts on streams such as increasing channel roughness, providing high flow refuge and cover for fish, forming scour pools, and regulating the transport of gravel through the river system (Mathias 2000). Our study area covered a distance of between $7.25 \mathrm{~km}$ and 9.0 $\mathrm{km}$ from the river mouth. The canalized segment was $1.15 \mathrm{~km}$ in length and the reconstructed segment was $0.5 \mathrm{~km}$ in length (Fig1).

\section{Study animals and transmitter attachment}

Pink and chum salmon spawn in the Shibetsu River system, and migrate through our study area during September and October, respectively. In 2004, 5 male chum salmon (fork length, 62.5-74.9 $\mathrm{cm}$; body weight 2.38-4.45 kg) and 5 male pink salmon (fork length, 51.0-59.7 cm; body weight $1.55-2.32 \mathrm{~kg}$ ) were caught in the Shibetsu River estuary and transferred to outdoor tank at the Shibetsu Salmon Museum.

An EMG transmitter (CEMG-R11, Lotek Engineering Inc., Newmarket, Ontario: $18.3 \mathrm{~g}$ in air, $8.0 \mathrm{~g}$ in water, $16.2 \mathrm{~mm}$ in diameter, $53.0 \mathrm{~mm}$ in length) and a DT logger (M190-DT, Little Leonardo Co. Ltd, Tokyo: $18 \mathrm{~g}$ in air, $47.5 \mathrm{~mm}$ in diameter, $14.5 \mathrm{~mm}$ in length) were 
attached to all experimental fish externally. The transmitter of and logger weight did not exceed $1.67 \%$ of the body weight for both species. Fish position and swimming speed were monitored using the EMG transmitter, and swimming depth was monitored using the DT logger. Using EMG transmitters and DT loggers simultaneously allow us to monitor the position of a fish horizontally and vertically. Experimental fish were anaesthetized using FA100 (eugenol; Tanabe Seiyaku Co. Ltd, Osaka, Japan) at a concentration of $0.5 \mathrm{ml} \mathrm{l}^{-1}$ in the Shibetsu River water, and total length and body weight were measured. The fish were placed on a surgical table, ventral side down, and their gills were irrigated with water containing with FA100 to maintain sedation during the procedure. An EMG transmitters and a DT logger were externally attached to the left side of the body, below the front edge of the dorsal fin, using nylon ties. The EMG transmitter and DT logger were sutured together using nylon ties and epoxy resin before the procedure. Using a needle, the nylon ties passed through a silicon pad, the upper part of the musculature, and a silicon pad opposite the EMG transmitter and DT logger. The silicon pads were attached to minimize abrasion. The EMG transmitters functioned by detecting muscle activity via brass sensing tips $(0.5 \times 0.1 \mathrm{~cm})$, connected to surgical steel electrode wires. The EMG electrodes were inserted subcutaneously using a hypodermic needle at about a 0.7 ratio of the body length on the left side of the fish. Two electrode tips were positioned approximately $10 \mathrm{~mm}$ apart, secured in the lateral red muscle toward the rear of the fish, which is primarily used in steady, non-bursting aerobic swimming activity (Geroge, 1962; Beddow and Mckinley, 1999). The electrodes also appear to be sensitive to contractions of the relatively larger white muscle (McKinley and Power, 1992; Hinch et al. 1996), which is recruited primarily during burst, anaerobic swimming. EMG signals can therefore generally be related to swimming speed (Økland et al. 1997). The electrodes were sutured to avoid entangling vegetation and/or structure in the field condition. An aminoglycoside antibiotic (Akiyama Seisakujyo 
Co. Ltd, Tokyo, Japan) was applied to the skin around the punctures and stitches. The attachment procedures usually required approximately five minutes to complete. After recovering from anaesthesia, we observed the behavior of the chum and pink salmon with EMG transmitters and DT loggers in a hatchery pond and, found no differences in behavior manner between the experimental fish and the intact fish.

\section{Calibration of EMG signals to swimming speeds}

Following the recovery period, we analyzed an individual calibration curve for convert EMG signals from the fish into swimming speeds. For the calibration, the fish were slowly forced to swim along a track (19 $\mathrm{m}$ in length, $5.5 \mathrm{~m}$ in width, and $0.67 \mathrm{~m}$ in depth) with a tape measure along the edge, and their swimming distance and travel time were measured. This trial was conducted about twenty times per individual until the fish were exhausted. EMG signals data were determined by EMG radio receivers (model SRX_400; Lotek Engineering Inc.) and recorded at 3-5 s intervals. When the fish maintained a holding position, non-moving EMG signals were also gathered. After this trial, we measured a flow in this track using an electromagnetic current meter (ES7603; Yokogawa Navi-tech Co. Ltd, Tokyo, Japan.). The relation between swimming speed and EMG signal output from tagged fish was plotted and used as a standard curve to estimate speeds in free swimming fish from collected EMG signals (McFarlane et al. 2004). Fish were transferred to a recovery live-box and allowed to recover in the release point of the Shibetsu River for one.

Field study

During September and October 2004, chum and pink salmon used in the EMG 
calibration were individually released $7.25 \mathrm{~km}$ upstream from the river mouth and tracked upstream to the end of the reconstructed segment on foot using a hand-held directional Yagi antenna. SRX 400 receivers recorded EMG signals at 3-5 s intervals. Migration time through both segments was measured for each fish by subtracting time of reach exit from time of reach entry. Ground speed was then calculated by dividing the segment length by the migration time. To compare the upstream swimming patterns between chum and pink salmon, we calculated the coefficient of variation (CV) for swimming speeds for each individual in both segments. We also calculated a swimming efficiency index (SEI) by dividing each individual's ground speed by its swimming speed. These data are useful for estimating an individual's energy utilization strategy. For instance, values below 1 indicate that individuals are swimming relatively hard to achieve forward progress, values equal to 1 imply relatively easy for forward progress (analogous to moving through still water), and values greater than 1 indicate that fish are receiving some type of forward assistance. EMG signals were converted to swimming speed using equations established from the EMG calibration.

After tracking, water depth and current speed were also measured at the locations along the river, every $50 \mathrm{~m}$, where fish positions were pinpointed and holding behavior were observed. Current speeds were measured at three layers (top, middle, and bottom) of the water column using an electromagnetic current meter. Daily average water temperatures were $3.9-15 \mathrm{C}$.

\section{Statistical analyses}

Regression analysis was performed by simple regression on EMG signals to swimming speed. Correlation coefficients were obtained using simple regression analysis (Excel software). Analysis of covariance (ANCOVA) was used to assess differences in condition between the specific weigh versus length regression relationships. Results 
were expressed as means \pm standard deviation of mean. Statistical significance was assessed at the 0.05 level. 


\section{Results}

Calibration of EMG signals to swimming speeds

Measurement of flow in the track revealed that there was no measurable flow, so we did not take account of flow in the track when calibrating EMG signals to swimming speeds. With simple regression analysis a significant correlation was found between EMG signals and swimming speed for both species (average of the 4 chum salmon $r^{2}=0.766$, and 3 pink salmon $r^{2}=0.80$, respectively; $P<0.05$ ). We removed three salmon (one chum salmon and two pink salmon) with $r^{2}<0.6$ from analysis of swimming speed. The equations from the simple regression analysis were individually used to convert EMG signals of the field study to each fish's swimming speed (For example, $y=0.044 x+0.0446 ; R^{2}=0.86$ for chum salmon \#1 Fig $2(a)$, and $y=0.06464 x-0.0759 ; R^{2}=$ 0.66 for pink salmon \#1 Fig 2(b)).

Field study

Upstream migration with the EMG transmitter and DT logger

All fish of both species migrated up the canalized segment, reached the confluence point with the reconstructed segment, and then entered the reconstructed meander. We retrieved 3 DT loggers for chum salmon and 2 DT loggers for pink salmon. Therefore data on swimming depths were obtained from three chum salmon and two pink salmon.

Table 1 summarizes the data on the swimming depth recorded from both tagged salmon species as well as measured current speed. ANCOVA for both species revealed that chum salmon (mean fork length $72.5 \pm 28.3 \mathrm{~cm}$, mean mass $3328 \pm 400 \mathrm{~g}$ ) were larger than the pink salmon (mean fork length $58.4 \pm 14.1 \mathrm{~cm}$, mean mass $2000 \pm 146.2 \mathrm{~g} ; \mathrm{P}$ $<0.05)$ used in this study. An average of swimming depth and current speed of chum 
and pink salmon were nearly the same (Table 1). An example of the typical pattern of upstream swimming behavior of both species is demonstrated in Fig. 3. Chum and pink salmon often migrated along the riverbanks and near the bottom of the water column, sometimes displaying holding behavior (cessation of swimming during their upstream migration for 5 minutes). Both species sometimes displayed backtracking and crossing behavior. However, we could find no clear relationships between these behaviors and swimming depth. Typical frequency distributions of swimming depth for chum salmon \#5 and pink salmon \#1 are shown in Fig. 4. Although modal swimming depth of chum salmon \#5 ranged 0.2 to $0.4 \mathrm{~m}$, modal swimming depth of pink salmon \#1 ranged 0.6 to $0.8 \mathrm{~m}$. The distributions of swimming depth of chum salmon showed lower peaks than pink salmon.

The general behavior of chum and pink salmon in the canalized and reconstructed segment

Table 2 summarizes the swimming behavior data about the swimming speeds calibrated from EMG data, CV of swimming speed, ground speed and SEI from chum and pink salmon. Swimming speeds ranged from 0.0301 to $2.20 \mathrm{BL} \mathrm{s}^{-1}$ for chum salmon (mean 0.718 $\mathrm{BL} \mathrm{s}^{-1}$ ) and from 0.053 to $3.27 \mathrm{BL} \mathrm{s}^{-1}$ for pink salmon (mean 1.24 $\mathrm{BL} \mathrm{s} \mathrm{s}^{-1}$ ). Mean values of swimming speed of chum and pink salmon were not widely different. Typical frequency distributions of swimming speed for chum salmon \#1 and pink salmon \#1 are shown in Fig. 5. Modal swimming speeds of chum salmon \#1 ranged 0.2-0.4 BL s${ }^{-1}$ and that of pink salmon $\# 1$ ranged 1.2-1.4 $\mathrm{BL} \mathrm{s}^{-1}$. The modal of swim speed of the pink salmon was higher than chum salmon.

We compared mean values of swimming speed, ground speed and SEI of chum and pink salmon between the canalized and reconstructed segments. A student's t-test 
revealed that mean values of swimming speed ( $P=0.478$ and 0.395$)$, ground speed $(P=0.395$ and 0.275$)$ and SEI $(P=0.848$ and 0.271$)$ of chum and pink salmon, respectively, for the canalized segment were not significantly different from the reconstructed segment.

Mean values of swimming speed between chum and pink salmon among the canalized and reconstructed segment were compared. A student's t-test revealed that mean values of swimming speed of both species were not significantly different in the canalized segment $(P=0.171)$, but these values of pink salmon were significantly higher than chum salmon in the reconstructed segment $(P=0.0037)$.

Mean values of ground speed between chum and pink salmon among the canalized and reconstructed segment were compared. A student's t-test revealed that mean values of swimming speed of pink salmon were significantly higher than chum salmon in both segments ( $P=0.0027$ and 0.037 , respectively).

Mean values of SEI of chum and pink salmon were compared between among the canalized and reconstructed segment. A student's t-test revealed that these values were not significantly different in both segments ( $P=0.744$ and 0.155 , respectively).

We compared CV of swimming speeds between chum and pink salmon among the canalized and reconstructed segments. A student's t-test revealed that CV of swimming speeds for chum salmon in the canalized segment were not significantly different from pink salmon $(P=0.339)$, but $C V$ of swimming speeds for chum salmon in the reconstructed segment were larger than pink salmon $(P=0.025)$ suggesting that chum salmon were changing their swimming speed more often than pink salmon in the reconstructed segment (Table 2).

We selected two individuals (chum salmon \#1 and pink salmon \#4) for a detailed segment-specific behavior of temporal patterns of instantaneous swimming speeds and 
swimming depth from DT logger (Fig 6). In order to clarify the differences between species that we observed in swimming patterns (Fig. $5 \mathrm{a}$ and $5 \mathrm{~b}$ ) and migration in relation to the segment characteristics. Chum and pink salmon each exhibited holding behavior (chum salmon \#1: 15:25:19-15:31:15 and 16:26:15-16:31:26; pink salmon \#4: 14:25:10-14:38:00 and 15:05:00-15:10:00). 


\section{Discussion}

In the present study, we used EMG transmitters and DT loggers to investigate the upstream migratory behavior of adult male chum and pink salmon. After the experimental attachment of EMG transmitters and DT loggers, we observed the behavior of experimental fish in the swim track, and could find no clear differences in behavior from intact individuals. Further, one fish (chum salmon \#3) with EMG transmitter and DT logger were caught in the upstream of fish ladder at the Kyousei bridge upstream $2.4 \mathrm{~km}$ from the reconstructed segment providing that the fish could pass the fish ladder. It is therefore likely that the salmon fitted with our EMG transmitters and DT loggers retain their homing motivation and maintain horizontal movement. Mellas and Haynes (1985) conducted experiments to determine the effects of various tag attachments on the swimming behavior of rainbow trout (Salmo gairdneri) and suggested that stomach tagging is the best method of transmitter attachment. Thorstad et al. (2000) conducted experiments to investigate the effects of external attachment and body-implanted dummy transmitters on the swimming performance of adult Atlantic salmon and suggested that there were no differences in endurance among untagged fish, fish with external transmitters and body-implanted transmitters. External transmitter placement has proven useful in studying gravid fish, with surgical implantation after spawning often resulting in higher mortality rate (Winter, 1996).

We found that chum and pink salmon swam parallel to and near the riverbank. This behavior is believed to be important for upstream migration of the adult migrants (Osborne, 1961; Brett, 1983). Generally, current speed of a river increases with distance away from the riverbank and the bed of the river (Henderson 1966). Adult pacific salmon stop feeding during their upstream migration and have to use stored energy reserves to complete their migration and spawning. So it is so important for all migrants to minimize 
upstream migration costs (Hughes 2004).

We described the swimming depth and swimming speed of chum and pink salmon during upstream migration in the Shibetsu River in detail. We found that the modal swimming depth of chum salmon was lower depth (0.2-0.4 m) than pink salmon (0.6-0.8 m) suggesting that pink salmon was swimming deeper than chum salmon. Furthermore, the modal swimming speed of chum salmon $\left(0.4-0.6 \mathrm{BL} \mathrm{s}^{-1}\right)$ was lower than pink salmon (1.2-1.4 BL s$\left.{ }^{-1}\right)$. Hertel (1966) estimated theoretically the residence that a fish experiences when swimming near the surface and found a relationship between submergence depth and the severity of wave drag. In accordance with Hertel's equation, this multiplier of energy expended will be 1 when the fish is swimming more than three body diameters beneath the surface and will peak at about 5 when the fish is swimming just a half of body diameter beneath the surface. Thus, a fish with a larger body diameter expends more energy when swimming near the surface of a river. Webb et al. (1991) investigated the effect of wave drag on the fast start performance of rainbow trout (O. mykiss) and found that in shallow water, wave drag accounted for $80 \%$ of the total resistance to acceleration. Mean water depth measured along the experimental section of the Shibetsu River was $0.78 \mathrm{~m}$, revealing that the Shibetsu River was a relatively shallow river. In our study, the average body diameter of pink salmon $(14.8 \pm$ $5.77 \mathrm{~cm})$ was larger than chum salmon $(13.7 \pm 7.07 \mathrm{~cm})$. Thus, adult male pink salmon with a larger body diameter have to expend more energy than chum salmon. The solid lines in Fig. 6 represent a depth, maximizing the wave drag calculated from individual body diameter using Hertel's equation. The depth maximizing the wave drag of chum salmon is shallower than pink salmon because of pink salmon's larger body diameter. Nicholas (2004) explained that large fish such as chinook salmon (O. tshawytscha) swim upstream further from the bank than smaller salmon such as sockeye, and found 
that fish optimize the trade-off between swimming in deeper water to reduce wave drag and swimming in shallower water to reduce skin friction and form drag. However, pink salmon used in our study were swimming in shallow depth in spite of expending high energy. We suppose that pink salmon could not optimize their swimming depth during upstream migration because of the shallow depth in the reconstructed segment of the Shibetsu River. We found that SEI of pink salmon was not significantly different between the canalized and reconstructed segments. However, pink salmon swam significantly faster than chum salmon in the reconstructed segment, suggesting that pink salmon used more energy than chum salmon in the reconstructed segment. It is becoming apparent that behavior is an extremely important factor affecting energy use (Rand \& Hinch 1998). In the reconstructed segment of the Shibetsu River, apparently the flow conditions are still not sufficiently complex to offer sufficient holding habitat for chum salmon in 2002 (Akita et al. 2006). We suspect that pink salmon may need to swim deeper than chum salmon to optimize energy use in the reconstructed segment. Relatively high levels of energy use may be cause pre-spawning mortality. The reconstructed segment of the Shibetsu River might have a shallower depth for upstream migration of pink salmon as a matured reconstructed segment. Thus, it is important for a river restoration to create a suitable river environment for upstream migration salmon considering species-specific migration behavior patterns.

A velocity and discharge of a river were also an important determinant of swimming patterns. Hinch et al. (1996) and Hinch \& Bratty, (2000) found that faster surface, turbulent and multidirectional currents in the Fraser River caused sockeye salmon to have difficulty locating appropriate migration paths, so individuals had to cross a river and they increased swimming speed variability. Our study was conducted in the Shibetsu River, which had relatively slow $\left(0.65 \mathrm{~m} \mathrm{~s}^{-1}\right.$ in September and $0.63 \mathrm{~m} \mathrm{~s}^{-1}$ in 
October) and less turbulent current. Hinch \& Rand (2000) found that upstream-migrating sockeye salmon adjusted their swimming speeds to achieve ground speeds when they were at less turbulent and slow water sites that resulted in energetically minimal costs. However, when the currents encountered were relatively fast and turbulent, sockeye salmon chose to swim relatively fast and not elicit this energy saving behavior. They speculated that at fast, turbulent sites, salmon might be attempting to minimize their travel times because they only have a short while to live and significant migration impediments could seriously affect arrival times on spawning grounds and hence negatively affect spawning success. The current condition of the Shibetsu River is relatively slow and calm, and salmon in the Shibetsu River do not need to migrate a long distance. Because the Shibetsu River is a slow and short river, energy may not be determined their behavior. The holding behavior may be a way to get them into a staging area so that they can await the arrival of other salmon for optimal spawning encounters. Male salmon in the Shibetsu River may wait for the females to show up so that the timing of mate selection and reproduction is optimized. Perhaps the differences between salmon species are an effect of differences in mate and/ or nest site selection or competition among males and their dominance hierarchy. We supposed that it was important to acknowledge that in 'easier' rivers, other selection pressures rather than energy availability, may be important.

Based on the present analyze chum and pink salmon are swimming with different behavior patterns. This information would be important for a restoration of river. In the United States, many stream restoration projects are undertaken, however, the performance of these projects is rarely assessed. Post-project performance evaluations (e.g., Morris and Moses 1999) are needed so that we can learn from our collective experiences and thereby improve future project design (Kondolf 1995). Kondlf (2000) indicated that to be successful river restoration must be account for geomorphic 
influence. In order to success the restoration project, information on species-specific upstream behavior patterns may be useful to create a suitable river habitat for each upstream migration salmon respectively in the future. However, in our study we used only male experimental fish. Hinch et al. (2002) found that sockeye and pink salmon solve their migration challenges by swimming with very different strategies, although the role of large size was not clear. Sockeye females are the same size as pink males yet their respective swimming patterns were different. To further clarify the difference in upstream migratory strategy between chum and pink salmon, studies that use additional methods, for example using female experimental fish and a large swimming tunnel capable of creating water velocities, are needed for better understanding of the differences in the upstream migratory behavior of chum and pink salmon. 


\section{Acknowledgements}

We thank the following people for their help and co-operation: M. Mizoguchi and A. Nitta (Japan NUS Co., LTD) for technical support, Dr. J. Leonard (Northern Michigan University) for assistance with the study design, and H. Kakizaki (Nemuro Salmon Propagative Association) for providing experimental animals. We also thank the staff of Hokkaido Farming Fisheries Promotion Corporation for their support. This study was supported in part by Grant in-Aid for scientific Research. (A) (18208017) from Japanese society for the promotion of science, and from the Foundation of Riverfront Improvement and Restoration. 


\section{References}

Akita, M., Y. Makiguchi, H. Nii, K. Nakao, JF. Sandahl, H. Ueda, 2006. Upstream migration of chum salmon through a restored segment of the Shibetsu River. Ecology of Freshwater Fish, 15: 125-130.

Beddow, T. A. \& R. S. McKinley, 1999. Importance of electrode positioning in biotelemetry studies estimating muscle activity in fish. Journal of Fish Biology, 54: 819-831.

Bernatchez, L. \&. J. J. Dodson, 1987. Relationship between bioenergetics and behavior in anadromous fish migrations. Canadian Journal of Fisheries and Aquatic Sciences 44: 399-407.

Brett, J.R., 1983. Life energetics of sockeye salmon, Oncorhynchus nerka. In Behavioral energetics: the cost of survival in vertebrates. Edited by N.P. Aspey and S.I. Lustick. Ohio State University Press, Columbus 29-63.

George, J.C., 1962. A histophysiological study of the red and white muscles of the mackerel. The American Midland Naturalist, 68: 487-494.

Henderson, F.M., 1966. Open channel flow. Collier Macmillan Canada Ltd., New York. 
Hertel, H. 1966. Structure form and movement. Reinhold, New York.

Hinch, S. G., E. M. Standen, M. C. Healey \& A. P. Farrell, 2002. Swimming patterns and behavior of upriver-migration adult pink (Oncorhynchus gorbuscha) and sockeye (O. nerka) salmon as assessed by EMG telemetry in the Fraser River, British Columbia, Canada. Hydrobiologia 483: 147-160.

Hinch, S. G. \& J. Bratty, 2000. Effects of swim speed and activity pattern on success of adult sockeye salmon migration through an area of difficult passage. Transactions of the American Fisheries Society 129: 598-606.

Hinch, S. G., \& P. S. Rand, 2000. Optimal swimming speeds and forward-assisted propulsion: energy-conserving behaviors of upriver-migrating adult salmon. Canadian Journal of Fisheries and Aquatic Sciences 57: 2470-2478.

Hinch, S. G. \& P. S. Rand, 1998. Swim speeds and energy use of upriver-migration sockeye salmon (Oncorhynchus nerka): role of local environment and fish characteristics. Canadian Journal of Fisheries and Aquatic Sciences 55: 1821-1831.

Hinch, S. G., R. E. Diewert, T. J. Lissimore, S.M.J. Prince, M.C. Healey \& M.A. Henderson, 1996. Use of electromyogram telemetry to assess difficult passage areas for river-migrating adult sockeye salmon. Transactions of the American Fisheries Society 125: 253-260.

Hughes, N. F., 2004. The wave-drag hypothesis: an explanation for size-based lateral 
segregation during the upstream migration of salmonids. Canadian Journal of Fisheries and Aquatic Sciences 61: 103-109

Kondolf, G. M., 1995. Learning from stream restoration projects. Proceedings of Fifth Biennial Watershed Management Conference. Ashland, Oregon, November 1994, California Water Resources Center Report No. 86: 107-110.

Kondolf, G. M., 2000. Some Suggested Guidelines for Geomorphic Aspects of Anadromous Salmonid Habitat Restoration Proposals. Society for Ecological Restoration 8: 48-56.

Leonard, J. B. K. \& S. D. McCormik, 1999. Effects of migration distance on whole-body and tissue-specific energy use in American shad (Alosa sapidissima). Canadian Journal of Fisheries and Aquatic Sciences 56: 1159-1171.

McFarlane, W.J., K.F. Cubitt, H. Williams, D. Rowsell, R. Moccia, R.Gosine \& R.S. McKinley, 2004. Can feeding status and stress level be assessed by analyzing patterns of muscle activity in free swimming rainbow trout (Oncorhynchus mykiss Walbaum)?. Aquaculture 239: 467-484.

McKinley, R.S. \& G. Power, 1992. Measurement of activity and oxygen consumption for adult lake sturgen (Acipenser fulvescens) in the wild using radio-transmitted EMG signals. In Wildlife telemetry: remote monitoring and tracking of animals. Edited by A.G. Priede and S.M. Swift. Ellis Horwood, West Sussex, U.K.: 307-318. 
Mellas, E. J. \& J. M. Haynes, 1985. Swimming performance and behavior of rainbow trout (Salmo gairdneri) and white perch (Morone americana): effects of attaching telemetry transmitters. Canadian Journal of Fisheries and Aquatic Sciences 42: 488-493.

Mizuno, N. \& K. Gose, 1981. Ecology of streams. Tokyo: Tsukiji-shokan, pp. 234. (in Japanese)

Morris, S., and T. Moses, 1999. Urban stream rehabilitation: a design and construction case study. Environmental Management 23(2):165-178.

Økland, F., B. Finstad, R. S. McKinley, E. B. Thorstad \& R. K. Booth, 1997. Radio-transmitted electromyogram signals as indicators of physical activity in Atlantic salmon. Journal of Fish Biology 51: 476-488.

Osborne, M.F.M., 1961. The hydrodynamic performance of migratory salmon. Journal of experimental biology 38: 365-390.

Rand, P. S. \& S. G. Hinch, 1998. Swim speeds and energy use of up-river migration sockeye salmon: simulating metabolic power and assessing risk of energy depletion. Canadian Journal of Fisheries and Aquatic Sciences 55: 1832-1841. 
Tanaka, H., Y. Takagi, M. Iwata \& Y. Naito, 1998. The behaviour and ambient temperature of homing chum salmon monitored by a data logger. Proceedings of the NIPR Symposium on Polar Biology 11: 62-73.

Tanaka, H., Y. Takagi \& Y. Naito, 2000. Behavioural thermoregulation of chum salmon during homing migration in coastal water. The Journal of Experimental Biology 203: $1825-1833$.

Tanaka, H., Y. Takagi \& Y. Naito, 2001. Swimming speeds and buoyancy compensation of migrating adult chum salmon Oncorhynchus keta revealed by speed/depth/acceleration data logger. The Journal of Experimental Biology 204: 3895-3904.

Thorstad, E. B., F. \& B. Finstad, 2000. Effects of telemetry transmitters on swimming performance of adult Atlantic salmon. Journal of Fish Biology 57: 531-535.

Webb, PW., D. Sims \& W. W. Scheltz, 1991. The effects of an air/water surface on the fast-start performance of rainbow trout (Oncorhynchus mykiss). The Journal of Experimental Biology 155: 219-226.

Winter, J.D, 1996. Advances in underwater biotelemetry. American Fisheries Society, Bethesda, Maryland : 555-590. 


\section{Legend of tables:}

Table 1. Sex, length, body mass, swimming depth and river current speed of chum and pink salmon. Values of swimming depth and river current speed are mean \pm S.D. Chum salmon

\begin{tabular}{cccccc}
\hline $\begin{array}{c}\text { Salmon } \\
\# .\end{array}$ & Sex & Fork length $(\mathrm{cm})$ & Body mass $(\mathrm{g})$ & $\begin{array}{c}\text { Swimming } \\
\text { depth }(\mathrm{m})\end{array}$ & $\begin{array}{c}\text { Current speeds } \\
\left(\mathrm{m} \mathrm{s}^{-1}\right)\end{array}$ \\
\hline 1 & $\mathrm{M}$ & 79.6 & 4100 & $0.732 \pm 0.246$ & $0.473 \pm 0.293$ \\
2 & $\mathrm{M}$ & 67.0 & 2380 & - & - \\
3 & $\mathrm{M}$ & 68.3 & 2860 & - & - \\
4 & $\mathrm{M}$ & 79.3 & 4450 & $0.717 \pm 0.308$ & $0.567 \pm 0.310$ \\
5 & $\mathrm{M}$ & 68.6 & 2850 & $0.342 \pm 0.338$ & $0.556 \pm 0.328$ \\
\hline Average & & $72.5 \pm 6.32$ & $3328 \pm 894$ & $0.597 \pm 0.221$ & $0.532 \pm 0.051$ \\
\pm S.D. & & & &
\end{tabular}

Pink Salmon

\begin{tabular}{cccccc}
$\begin{array}{c}\text { Salmon } \\
\# .\end{array}$ & Sex & Fork length $(\mathrm{cm})$ & Body mass $(\mathrm{g})$ & $\begin{array}{c}\text { Swimming } \\
\text { depth }(\mathrm{m})\end{array}$ & $\begin{array}{c}\text { Current speeds } \\
\left(\mathrm{m} \mathrm{s}^{-1}\right)\end{array}$ \\
\hline 1 & $\mathrm{M}$ & 53.6 & 1550 & $0.678 \pm 0.256$ & $0.543 \pm 0.309$ \\
2 & $\mathrm{M}$ & 60.4 & 2320 & - & - \\
3 & $\mathrm{M}$ & 60.3 & 2130 & - & - \\
4 & $\mathrm{M}$ & 61.0 & 2230 & $0.429 \pm 0.244$ & $0.590 \pm 0.325$ \\
5 & $\mathrm{M}$ & 56.9 & 1770 & - & - \\
Average & & $58.4 \pm 315$ & $2000 \pm 327$ & 0.556 & 0.567 \\
\pm S.D. & & & &
\end{tabular}


Table 2. Summary for swimming speed, CV of swimming speed, ground speed and SEI of chum and pink salmon. Values are mean \pm S.D.

Chum Salmon

\begin{tabular}{ccccccccc}
\hline \multirow{2}{*}{$\begin{array}{c}\text { Salmon } \\
\# .\end{array}$} & \multicolumn{2}{c}{ Swimming speeds $\left(\mathrm{BL} \mathrm{s}^{-1}\right)$} & \multicolumn{2}{c}{ CV of swimming speeds $\left(\mathrm{BL} \mathrm{s}^{-1}\right)$} & \multicolumn{2}{c}{ Ground speeds $\left.(\mathrm{BL} \mathrm{s})^{-1}\right)$} & SEI \\
\cline { 2 - 8 } & Canalized & Reconstructed & Canalized & Reconstructed & Canalized & Reconstructed & Canalized & Reconstructed \\
segment & segment & segment & segment & segment & segment & segment & 0.449 \\
\hline 1 & $0.747 \pm 0.272$ & $0.586 \pm 0.317$ & 0.463 & 0.68 & $0.230 \pm 0.163$ & $0.263 \pm 0.309$ & - & 0.31 \\
2 & $1.44 \pm 0.232$ & - & 0.161 & - & $0.142 \pm 0.170$ & - & 0.09 & 0.57 \\
3 & $0.478 \pm 0.177$ & $0.533 \pm 0.309$ & 0.369 & 0.58 & $0.271 \pm 0.363$ & $0.138 \pm 0.141$ & 0.259 \\
4 & $0.45 \pm 0.167$ & $0.454 \pm 0.211$ & 0.445 & 0.464 & $0.364 \pm 0.371$ & $0.305 \pm 0.193$ & 0.81 & 0.672 \\
5 & $0.749 \pm 0.479$ & $0.867 \pm 0.484$ & - & - & $0.316 \pm 0.712$ & $0.215 \pm 0.116$ & 0.42 & 0.248 \\
\hline average \pm S.D. & $0.773 \pm 0.399$ & $0.610 \pm 0.179$ & $0.360 \pm 0.138$ & $0.575 \pm 0.108$ & $0.265 \pm 0.085$ & $0.230 \pm 0.072$ & $0.439 \pm 0.270$ & $0.407 \pm 0.199$
\end{tabular}

Pink Salmon

\begin{tabular}{|c|c|c|c|c|c|c|c|c|}
\hline \multirow{2}{*}{$\begin{array}{l}\text { Salmon } \\
\quad \# .\end{array}$} & \multicolumn{2}{|c|}{ Swimming speeds $\left(B L s^{-1}\right)$} & \multicolumn{2}{|c|}{$\mathrm{CV}$ of swimming speeds $\left(\mathrm{BL} \mathrm{s}^{-1}\right)$} & \multicolumn{2}{|c|}{ Ground speeds $\left(B L ~ s^{-1}\right)$} & \multicolumn{2}{|c|}{ SEI } \\
\hline & $\begin{array}{l}\text { Canalized } \\
\text { segment }\end{array}$ & $\begin{array}{c}\text { Reconstructed } \\
\text { segment }\end{array}$ & $\begin{array}{l}\text { Canalized } \\
\text { segment }\end{array}$ & $\begin{array}{c}\text { Reconstructed } \\
\text { segment }\end{array}$ & $\begin{array}{l}\text { Canalized } \\
\text { segment }\end{array}$ & $\begin{array}{l}\text { Reconstructed } \\
\text { segment }\end{array}$ & $\begin{array}{l}\text { Canalized } \\
\text { segment }\end{array}$ & $\begin{array}{c}\text { Reconstructed } \\
\text { segment }\end{array}$ \\
\hline 1 & $0.979 \pm 0.444$ & $1.28 \pm 0.421$ & 0.453 & 0.329 & $0.490 \pm 0.383$ & $0.79 \pm 0.995$ & 0.501 & 0.617 \\
\hline 2 & $1.26 \pm 0.250$ & $1.43 \pm 0.440$ & 0.199 & 0.308 & $0.664 \pm 0.212$ & $1.56 \pm 1.47$ & 0.527 & 1.09 \\
\hline 3 & - & - & - & - & - & - & - & - \\
\hline 4 & $1.23 \pm 0.260$ & $1.12 \pm 0.372$ & 0.211 & 0.333 & $0.561 \pm 0.381$ & $0.543 \pm 0.411$ & 0.456 & 0.485 \\
\hline 5 & - & - & - & - & - & - & - & - \\
\hline $\operatorname{ge} \pm S$. & $1.16 \pm 0.154$ & $1.28 \pm 0.155$ & $0.288 \pm 0.143$ & $0.323 \pm 0.013$ & $0.572 \pm 0.087$ & $0.964 \pm 0.530$ & $0.495 \pm 0.036$ & $0.73 \pm 0.319$ \\
\hline
\end{tabular}




\section{Legend of figures:}

Figure 1. Map of Shibetsu River indicating the canalized segment and the reconstructed segment.

Figure 2. Relationships between electromyogram pulse interval (EMGPI) and swimming speed (BL s $\left.{ }^{-1}\right)$ for chum salmon \#3 (a) and pink salmon \#1 (b).

Figure 3. Map of the study area showing the upstream migratory route (lines within river) and vertical position of chum salmon \#1 (a) and pink salmon \#1 (b). Numbers along the river correspond with the numbers above the diagrams below, indicating the horizontal location of the fish. The points inside the diagram show the horizontal and vertical position of the fish. Open points indicate a holding behavior, and closed points indicate a moving behavior.

Figure 4. Frequency distributions of swimming depth for chum salmon \#5 (a) and pink salmon \#1 (b) for the entire recording period.

Figure 5. Frequency distributions of swimming speed for chum salmon \#1 (a) and pink salmon \#1 (b) for the entire recording period. 
Figure 6. Time-series plots of swimming speeds for chum salmon \#1 (a) and pink salmon \#4 (b).The solid lines represent a depth maximizing the wave drag calculated from individual' body diameter using Hertel's equation. The dotted lines represent holding periods of chum and pink salmon. 


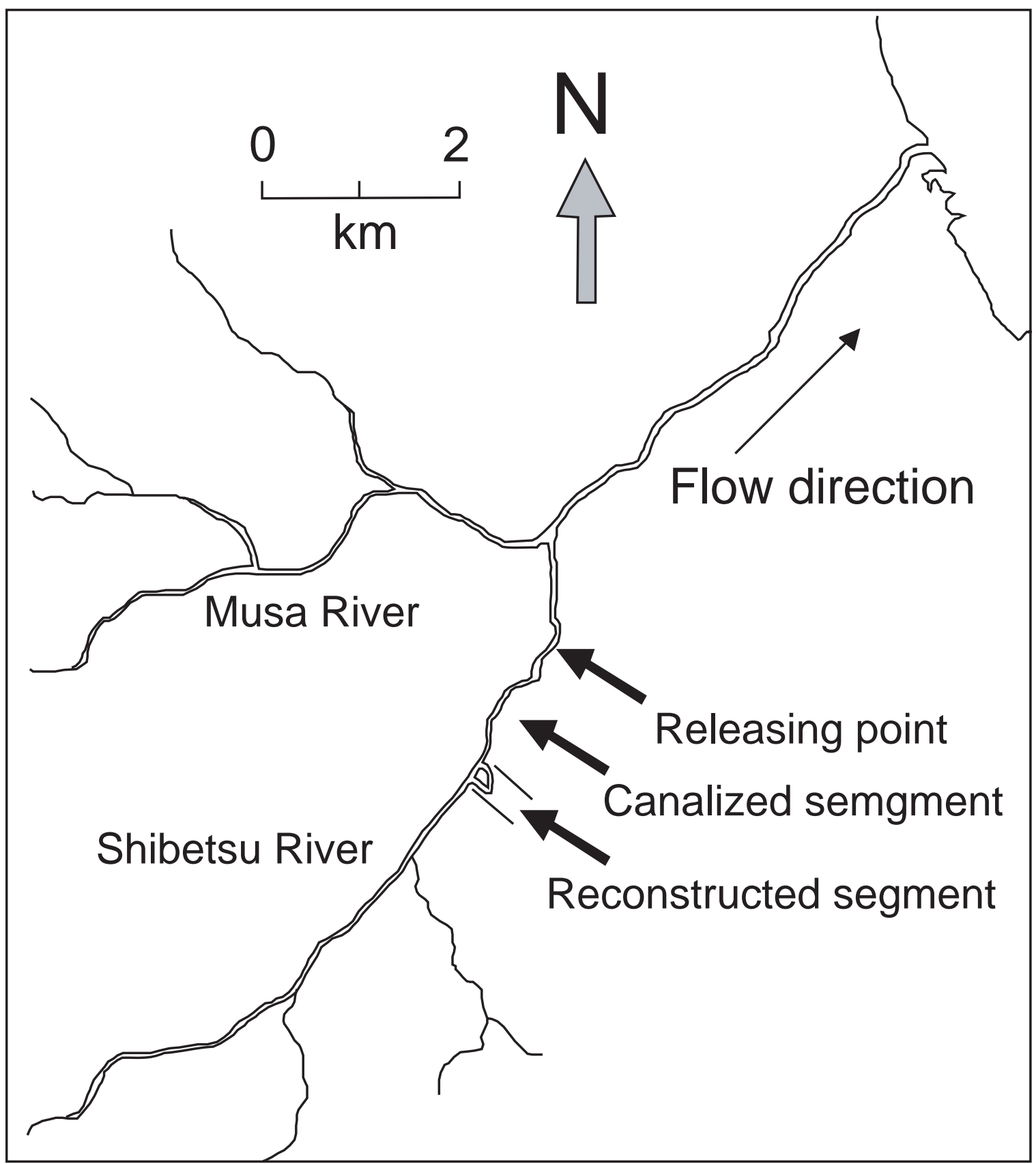

Canalized semgment Reconstructed segment

Flow direction

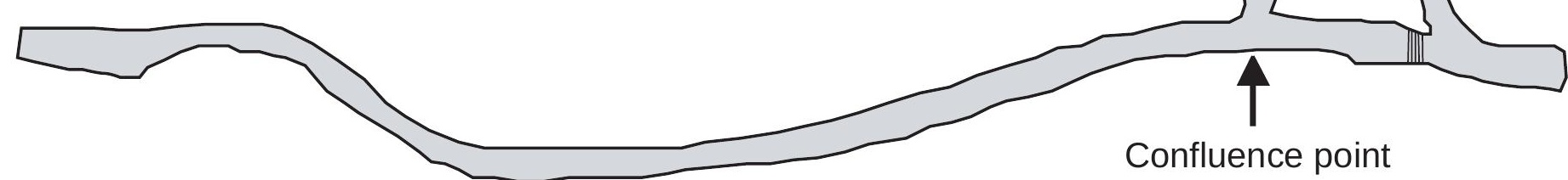




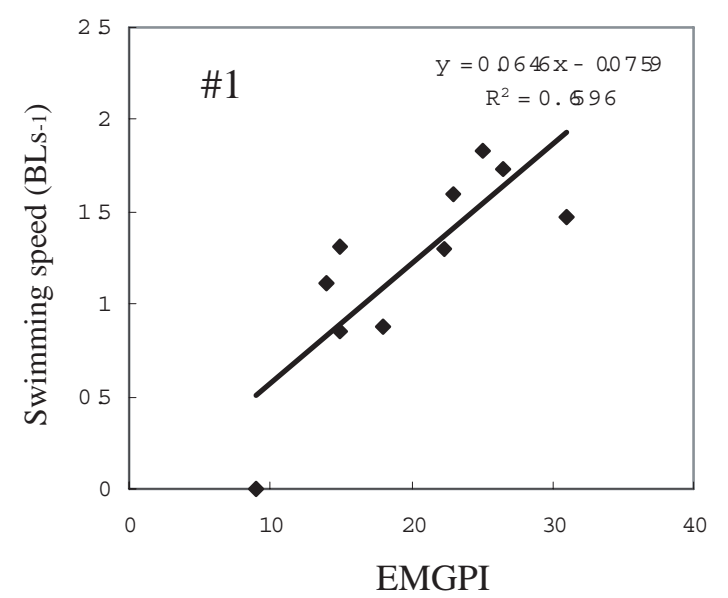

Fig 2b 
Fig 3b
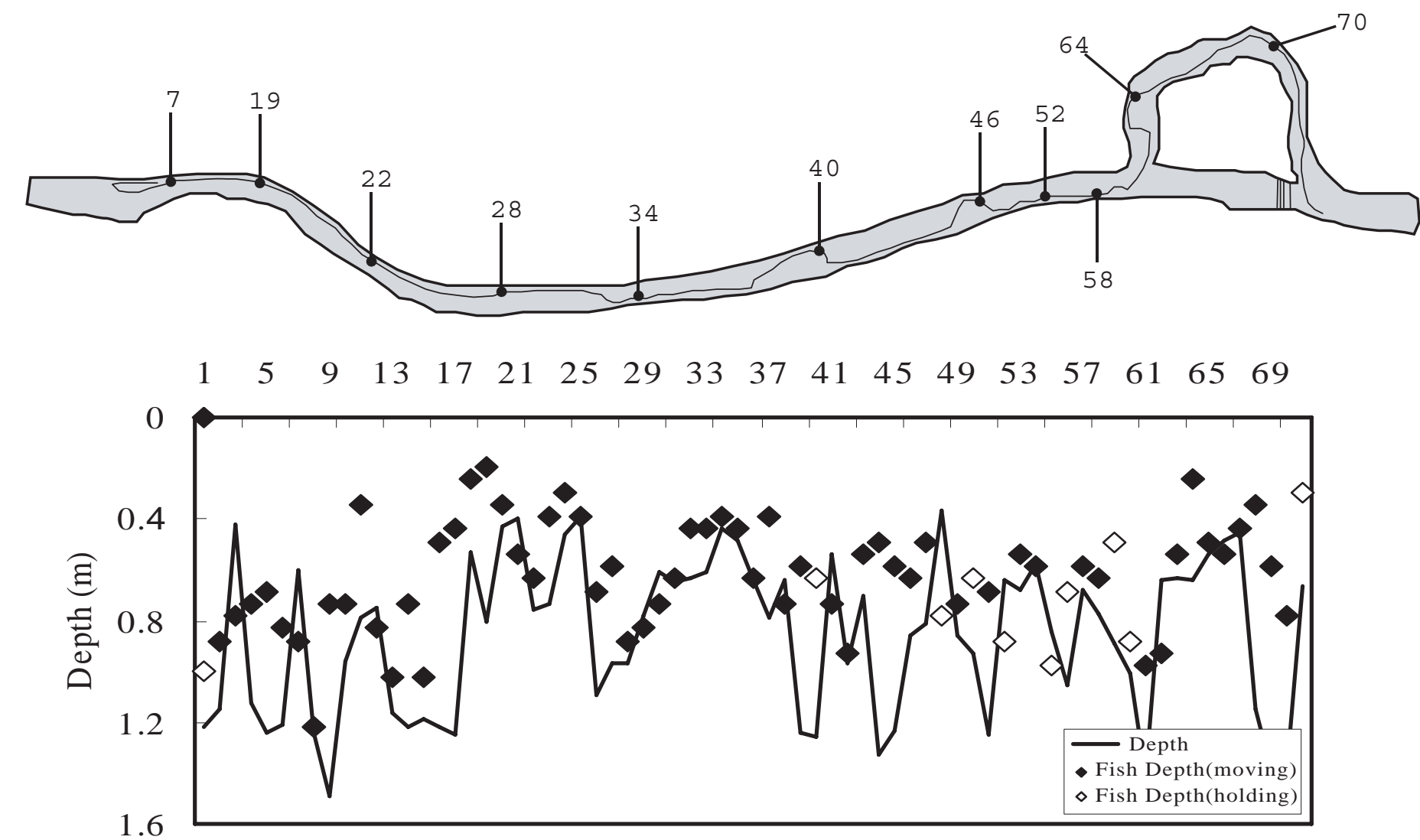
Fig $4 a$

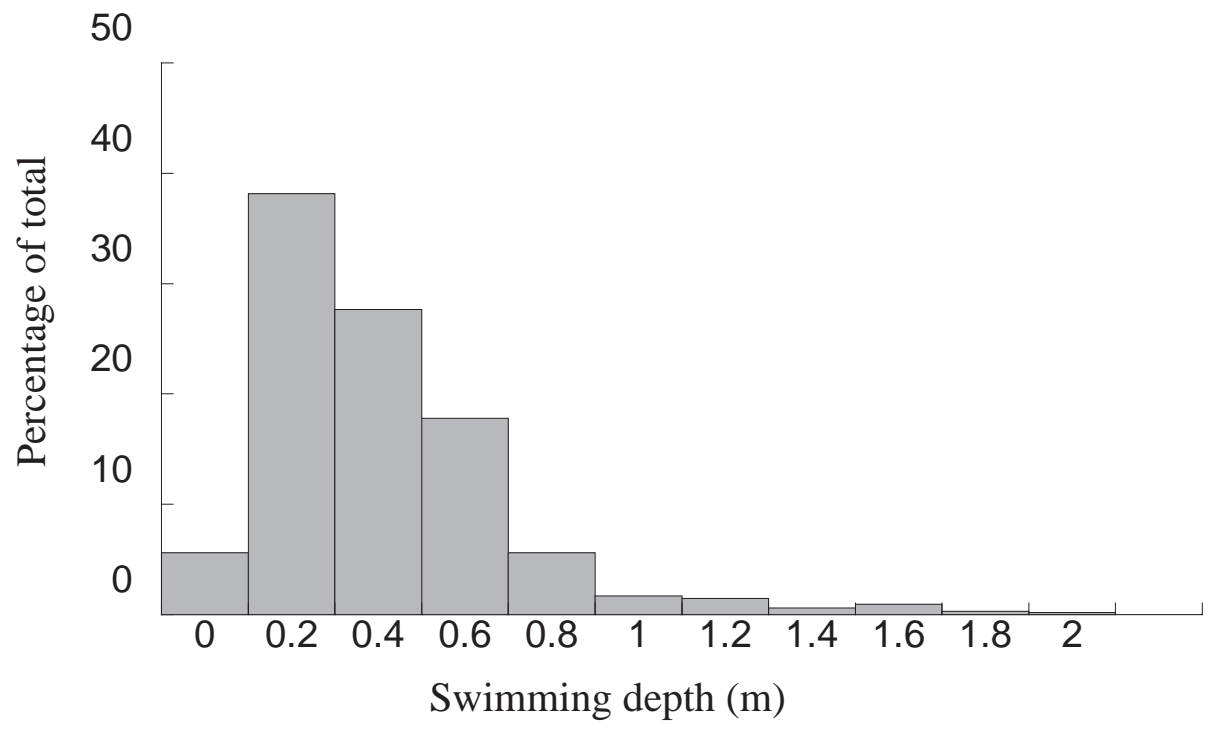


Fig 4b

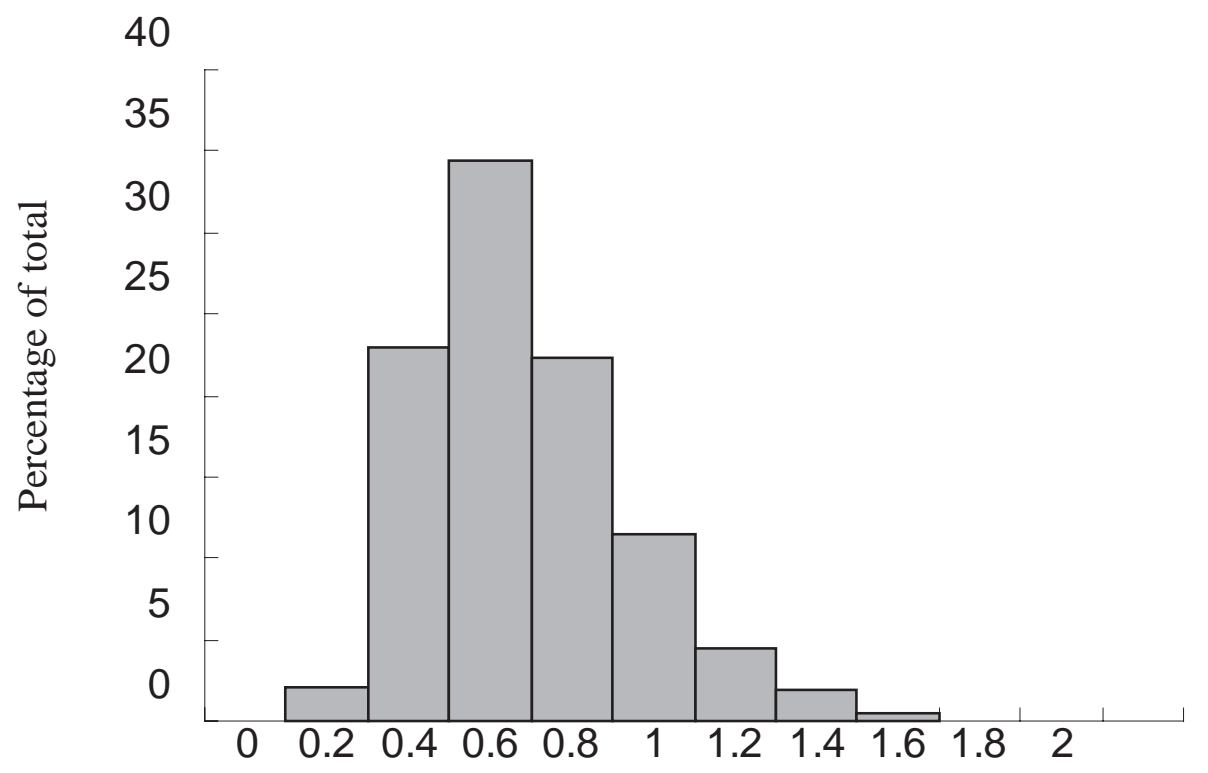

Swimming depth (m) 
Fig $5 a$

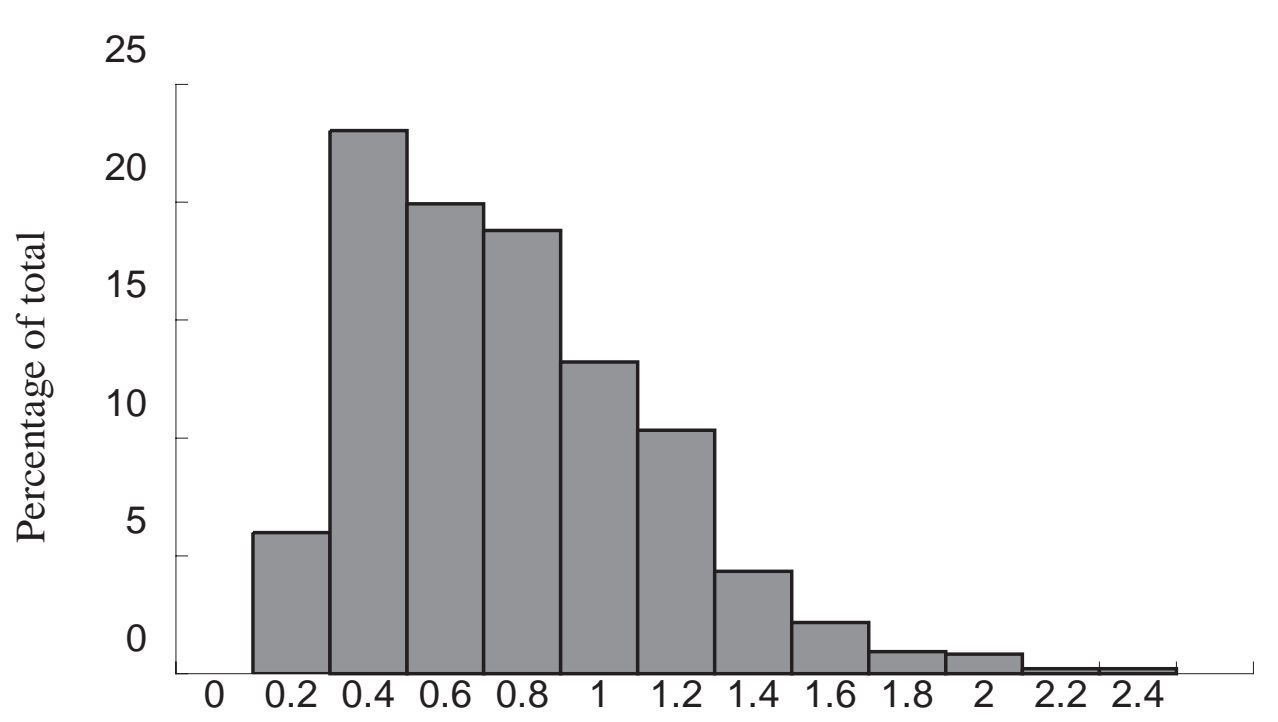

Swimming speed (BLs-1) 
Fig 5b

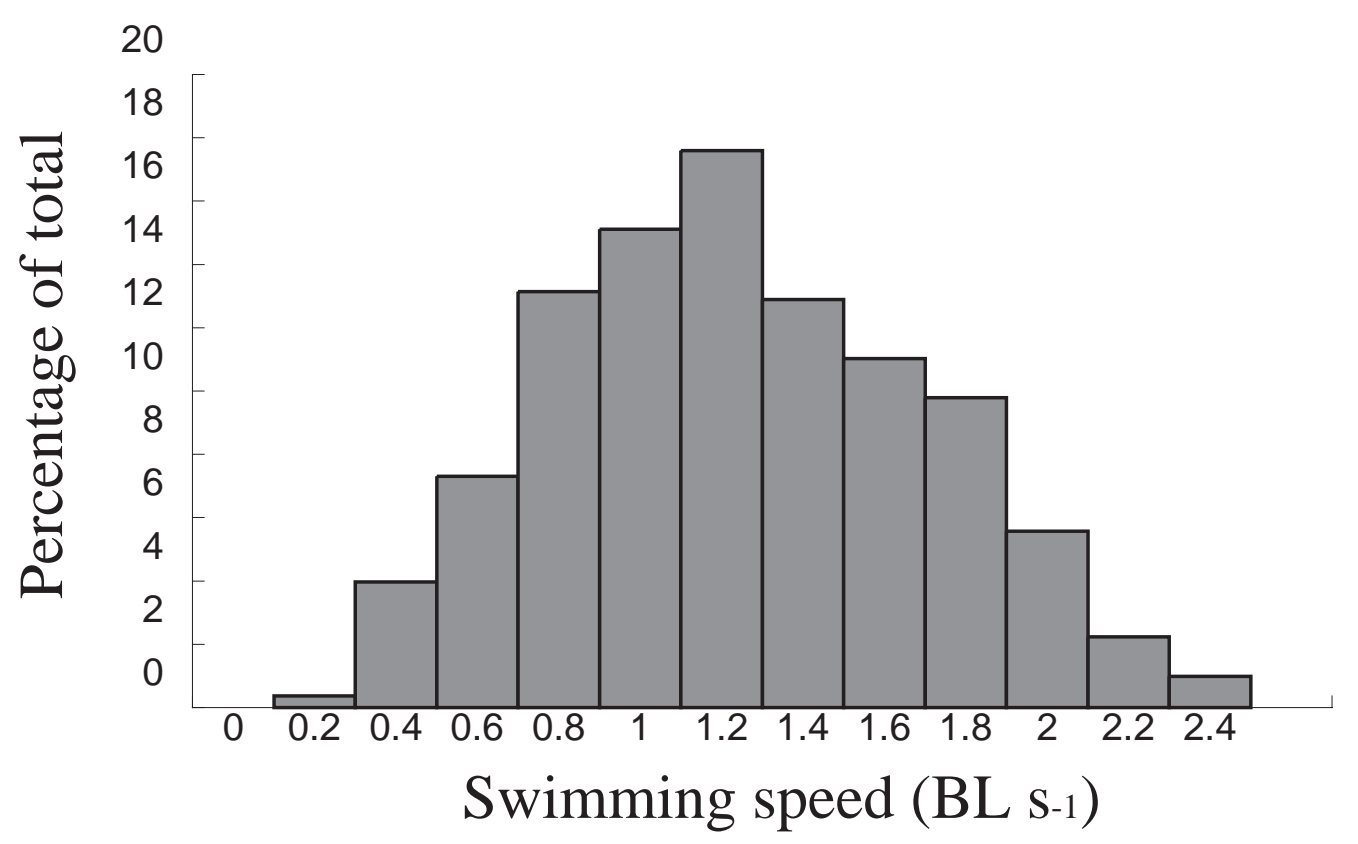




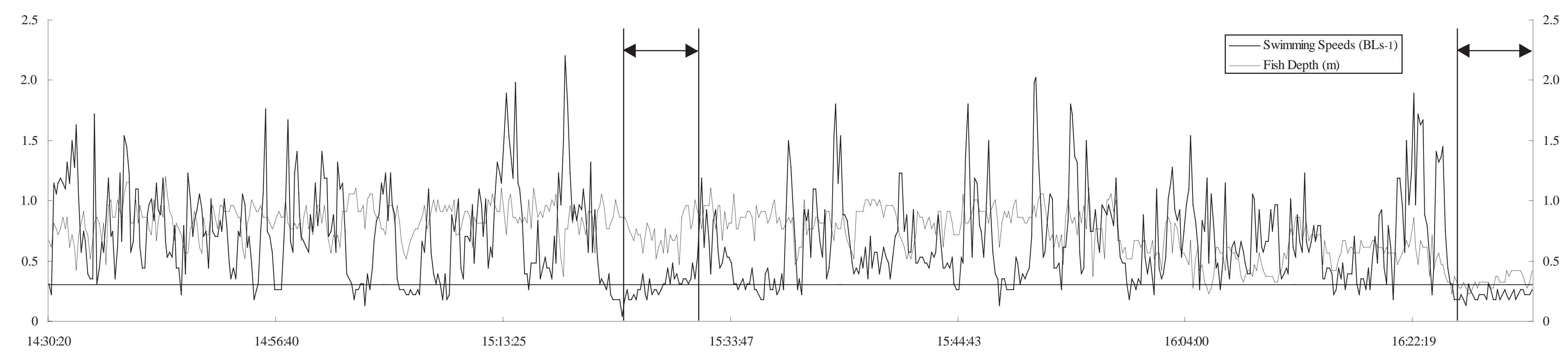




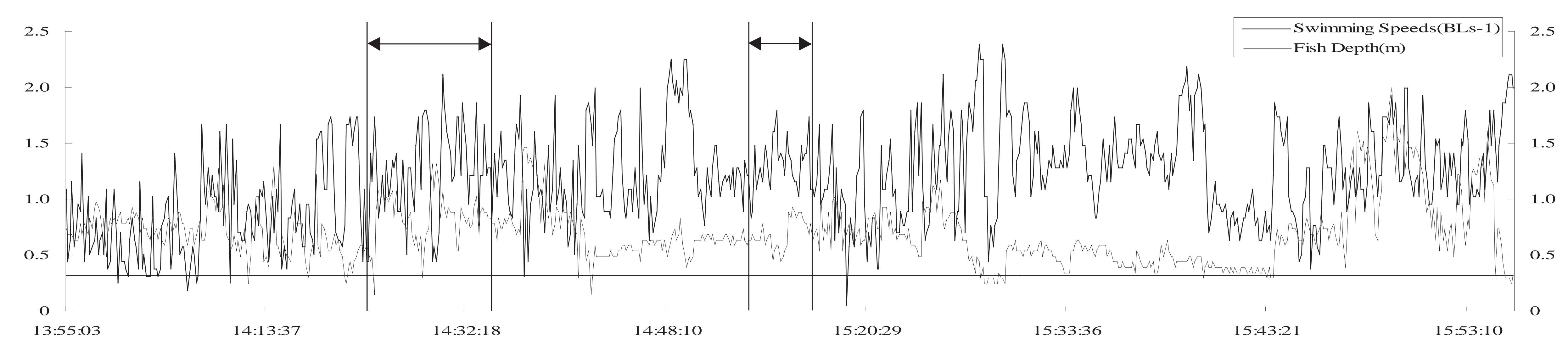

